\title{
Las personas en situación de calle y el rol de la universidad
}

\author{
Homeless people and University's role
}

\begin{abstract}
Claudio Seebach
Claudio Seebach es ingeniero civil de industrias mención electricidad de la Universidad Católica y M.Sc. in Management Science and Engineering, Stanford University. Además es Director Ejecutivo del Programa de Políticas Públicas UC y Profesor Auxiliar Asociado del Departamento de Ingeniería Industrial UC y del Instituto de Ciencia Política UC. Socio de la consultora Nueva Vía, dedicada a temas de infraestructura y concesiones, es también miembro del Directorio Nacional del Hogar de Cristo. Dirección postal El Comendador 1916, 753-0091, Providencia, Santiago - Chile. Email: cseebach@ing.puc.cl
\end{abstract}

El año 2005 fue el año de la canonización de Padre Alberto Hurtado s.j., hombre santo que dedicó su vida por lo más pobres de los pobres, y muy especialmente los que vivían en la calle, bajo los puentes, debajo de un banco de la plaza, solo cubiertos con cartones o alguna harapo que los cubriera en las frías noches de nuestro país.

No mucho ha cambiado desde aquellos tiempos, y hoy, a pesar de nuestra integración internacional, de nuestro preciado crecimiento económico y de haber tenido el precio del cobre en las nubes, las personas en situación de calle viven en condiciones iguales o peores que hace 50 años. Tal vez hayan mejorado sus condiciones materiales en algunos casos, pero el abandono de la sociedad sigue siendo el mismo.

Pero algunas cosas si han cambiado para ellos: durante el 2005 ocurrió un hecho inédito para estos queridos amigos de Alberto Hurtado. Distintas instituciones del Estado, de la Iglesia y de la Sociedad Civil decidieron unirse para participar en un proceso que buscaba hacer visible la realidad de las personas que viven en situación de calle, conocer cuantos son, donde viven y escuchar sus necesidades.

Fue en este marco que se realizó el Primer Catastro Nacional de Personas en Situación de Calle, que dio cuenta de más de 7 mil personas que no gozan de los derechos humanos más fundamentales. Esta actividad permitió dimensionar el problema, constatar su complejidad y logró instalarlo en la agenda pública.

Luego, durante el mes de agosto del 2005, la Red de Organizaciones para el Trabajo con Personas en Situación de Calle, organizó la realización de 60 asambleas locales, en todas las regiones del país.
El objetivo era establecer las acciones de mayor urgencia, que tanto el Estado como la Sociedad Civil deberían implementar para contribuir a superar sus condiciones particulares de vida, profundizando los resultados de las consultas participativas desarrolladas durante el 2004 por el Hogar de Cristo, en el marco del proyecto "Radiografía Humana de la Pobreza".

En estas asambleas las propias personas que viven en situación de calle definieron cuatro grandes ámbitos de acción: integración, empleo, vivienda y salud mental, y para cada una de ellas, propusieron ideas generales. Todo lo anterior fue sistematizado en un documento que fue entregado al Presidente del Senado, a la Ministra de Planificación y a un representante del mundo empresarial, el día martes 4 de octubre en el propio Congreso Nacional. La Pontificia Universidad Católica de Chile, a través del Programa de Políticas Públicas, tuvo el honor de ser invitada como representante del mundo académico a recibir este "Informe Ejecutivo de Resultados de las Asambleas Regionales".

Lo anterior constituye no solo un honor para nuestra Universidad, sino una clara responsabilidad en los esfuerzos del país para transformar estos legítimos anhelos, en oportunidades concretas para quienes viven en situación de calle.

Fue así como el 25 de noviembre de 2005 la Universidad se hizo cargo de este hito y organizó en conjunto con MIDEPLAN y el Hogar de Cristo un encuentro donde fue lanzado el libro con los resultados del Primer Catastro de Personas en Situación de Calle, además de una muestra fotográfica. Este encuentro que contó con la presencia de gen- 
te en situación de calle, además de la Ministra de Planificación, Yasna Provoste, el rector de nuestra universidad Pedro Pablo Rosso, el Capellán General del Hogar de Cristo, P. Augustín Moreira s.j., el Director Social del Hogar de Cristo, Benito Baranda, el Jefe de la División Social del Ministerio de Planificación, Andrés Jouanett, y cuatro destacados invitados que dieron sus visiones de cómo abordar el problema de las personas en situación de calle a la luz de los resultados del catastro y de las asambleas. Ellos son María Teresa Matus, Profesora de la Escuela de Trabajo Social UC, Ricardo Mena, Coordinador Social de Moviliza, Ignacio Irarrázaval, Director de Asuntos Públicos UC y Sebastián
Zulueta, ex Director Ejecutivo y Voluntario de la Corporación Nuestra Casa.

Este encuentro debe ser considerado como el inicio de un involucramiento más profundo, serio y sistemático en el problema de las personas en situación de calle desde lo que la universidad sabe hacer mejor: investigar, enseñar y desarrollar ideas innovadoras para aportar a que Chile sea un país donde no sea necesario vivir en la calle. Esta es la responsabilidad de nuestra universidad, una universidad católica, con una profunda vocación de servir al país, más aun si sabemos que siempre contaremos en esta tarea con la guía de San Alberto Hurtado. 